\title{
Identification of Mycobacteria by Overall Similarity Analysis
}

\author{
By VIORICA BOGDANESCU AND R. RACOTTA \\ Institutul Clinic de Ftiziologie, Sos.Viilor 90, Bucharest, Romania
}

(Accepted for publication 21 February 1967)

SUMMARY

\begin{abstract}
Morphological, physiological, growth and chemosusceptibility characters were determined for 80 'atypical' acid-fast and 3 non acid-fast strains isolated from tuberculous, or presumed tuberculous, patients, and for 24 control strains belonging to various mycobacterial species. Overall similarity analysis was used for establishing the relationships upon the basis of 60 characters codified by 153 features.

The overall analysis differentiated five clusters having mean matching indices above $80 \%(80$ phenon $=80 \mathrm{P})$, namely: $80 \mathrm{P}-\mathrm{I}$ (human and bovine mycobacteria); $80 \mathrm{P}$-II ('atypical' mycobacteria belonging to the Ist, IInd and IIIrd Runyon groups); 80P-III (mycobacteria related to Mycobacterium fortuitum); 80P-IV (scotochromogenic mycobacteria with greater metabolic abilities); 80P-V (M. smegmatis). Nine strains (among which were three non acid-fast bacilli) were not included in these clusters.

The 'atypical' mycobacteria cluster (80P-II) was formed by three clearly delimited subgroups, which broadly corresponded to Runyon's classification.

A more detailed analysis of certain groups, and the determination of the characters of some 'hypothetical average organisms', allowed the further differentiation of some subgroups and aberrant strains.

The need to standardize the coding methods is stressed. Because of the value of overall similarity in such a variable genus, an international system to classify and identify strains upon a phenetic basis is suggested.
\end{abstract}

\section{INTRODUCTION}

Classification on a phenetic basis (overall similarity analysis, numerical taxonomy, Adansonian classification), using the method suggested by Sneath (1957) and Sneath \& Cowan (1958), has found followers in various branches of microbiology: Hill (1959); Gilardi, Hill, Turri \& Silvestri (1960); Talbot \& Sneath (1960); Hill, Turri, Gilardi \& Silvestri (1961); Colwell \& Liston (1961); Beers \& Lockhart (1962); Beers, Fisher, Megraw \& Lockhart (1962); Silvestri, Turri, Hill \& Gilardi (1962); Liston, Wiebe \& Colwell (1963); Proctor \& Kendrick (1963); Colwell \& Mandel (1964); Kendrick \& Proctor (1964). It was debated at the 17th International Congress of Microbiology at Montreal, at a symposium of the Systematics Association (Heywood \& McNeill, 1964), at the Conference at Quebec in 1964; it has been the object of theoretical discussions, e.g. Lysenko \& Sneath (1959), Floodgate (1962a, b), Sattler (1963), Reynolds (1965), and a book has been published on this subject by Sokal \& Sneath (1963).

This shows the interest roused by a method that offers a chance to end much doubt that exists in the systematics of micro-organisms. The correlations between DNA 
relationships (Marmur, Falkow \& Mandel, 1963) and those obtained by phenetic analysis (Colwell \& Mandel, 1964, 1965; Silvestri \& Hill, 1965) emphasize the value of the method.

Concerning the mycobacteria, precise studies of the relationship between known species have been carried out with immunological techniques (Siebermann \& Barbara, 1964; Koyama, 1964; Kassirskaia \& Mencikov, 1965), or with bacteriophages (Manion, Bradley, Zinneman \& Hall, 1964). Numerical taxonomy was applied to the study of mycobacteria mainly by Mexican research workers: Bojalil \& Cerbón (1961); Cerbón \& Bojalil (1961); Bojalil, Cerbón \& Trujillo (1962), as well as by Wayne \& Doubek (1963), enabling them to systematize the material and to describe new species.

In the pathological material examined in our laboratories mycobacteria of a type other than human or bovine were frequently found (Nasta \& Bogdanescu-Cioclov, 1959; Bogdanescu, Bungetianu \& Racotta, 1965). Since classification based upon some of the simple characters (Runyon, 1959; Collins, 1962; Marks \& Richards, 1962; Buraczewska, 1963; Kagramanov, 1963) was not completely satisfactory, we have tried to classify the strains on a phenetic basis.

\section{Methods}

Strains. Twenty-four previously identified strains (Table 1) and 78 strains isolated from 78 tuberculous, or presumed tuberculous, patients (mainly from sputa) were examined. Variants with different cultural characters, developed spontaneously or obtained by passage through mice from 5 of the 78 strains, have been included as separate strains.

Tests. We studied 60 characters that may be subdivided into 9 groups:

(1) Morphological characters of growth (smooth or rough, eugonic or dysgonic) on Löwenstein-Jensen medium ( $\mathrm{LJm}$ ), after 30 days incubation (examined with a hand lens.)

(2) Texture characters of growth after 8-15 incubation days on LJm (Marks \& Richards, 1962): adherence to the medium, viscosity, texture (granular or butyrous), emulsibility in distilled water.

(3) Microscopic characters after 30 days on LJm: true branching (slide culture in Youman medium), cording, shape (bacilli, coccobacilli), length, thickness (measured with the ocular micrometer), percentage of acid-fast micro-organisms, depth of staining.

(4) Ability and rate of growth on two media ( $\mathrm{LJm}$ and $7 \%$ glycerol agar) at three different temperatures $\left(25^{\circ}, 37^{\circ}\right.$ and $\left.45^{\circ}\right)$ after loop inoculation $(3 \mathrm{~mm}$ diam.) of a $10^{-2} \mathrm{mg} . / \mathrm{ml}$. bacillary dilution.

(5) Pigmentation in light and dark (Juhlin, 1960).

(6) Drug resistance (percentage method of Canetti, Rist \& Grosset, 1963): INH $(0 \cdot 2,1$ and $100 \mu \mathrm{g} . / \mathrm{ml}$.); PAS-acid (1 and $10 \mu \mathrm{g} . / \mathrm{ml}$.); ethionamide $(20 \mu \mathrm{g} . / \mathrm{ml}$.); cycloserine ( $25 \mu \mathrm{g} . / \mathrm{ml}$.); thiosemicarbazone (10 and $40 \mu \mathrm{g} . / \mathrm{ml}$.).

(7) Presence of certain enzymes and vitamins: catalase (Peizer \& Widelock, 1955); nicotinamide (Konno, 1960); nitrate reductase (Virtanen, 1960); acetamidase, benzamidase, urease, nicotinamidase, salicilamidase, succinamidase (after $24 \mathrm{hr}$, Bönicke, 1960).

(8) Ability and rate of utilization of certain amino acids and organic salts: DL- 
alanine (Käppler \& Janowiec, 1963); sodium acetate, benzoate, citrate, lactate, oxalate, pyruvate, propionate, succinate and tartrate (Gordon \& Smith, 1953), after incubation of $0.2 \mathrm{ml}$. from a $1 \mathrm{mg}$. $/ \mathrm{ml}$. bacillary dilution.

\section{Table 1. List of strains from culture collections or previously identified}

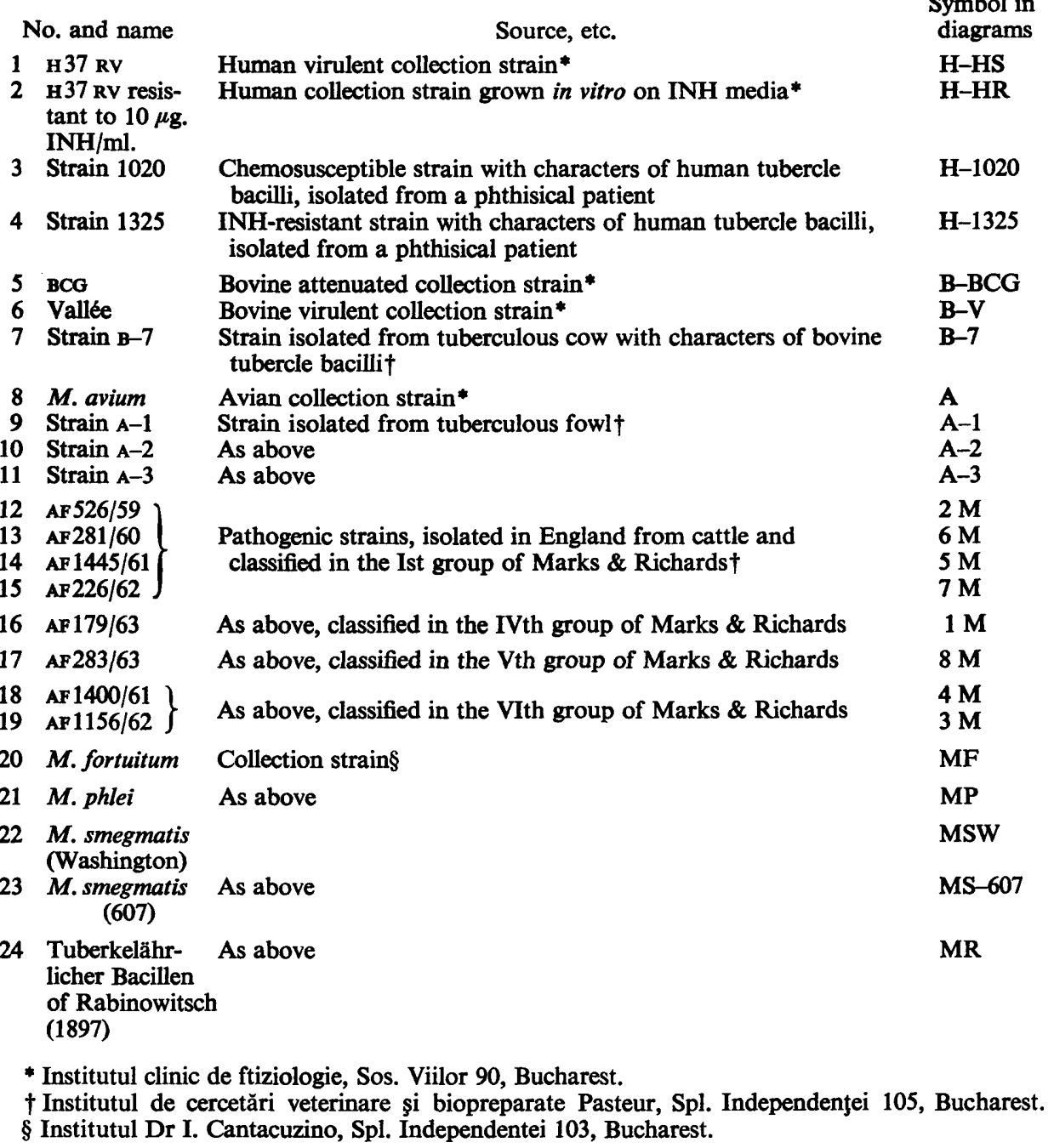

(9) Ability and rate of fermentation of certain sugars and higher alcohols (Gordon \& Smith, 1953): arabinose, galactose, glucose, lactose, maltose, mannose, raffinose, rhamnose, trehalose, xylose, dulcitol, inositol, mannitol and sorbitol (incubation as for 8).

In order to estimate growth rate, the importance of which in the genus Mycobacterium was emphasized by Wayne (1964), we recorded the time growth became visible in the 4th group of tests (2-28 days incubation), and the time the medium changed colour in the 8th and 9th groups of tests (up to 60 days incubation). 
Coding methods. Methods very similar to those suggested by Silvestri et al. (1962) were used as follows:

(1) Quantitative data:

(a) Silvestri et al. 1962:

\begin{tabular}{cccc}
$\begin{array}{c}\text { Degree of the } \\
\begin{array}{c}\text { quantitative } \\
\text { character }\end{array}\end{array}$ & \multicolumn{3}{c}{ Computed features } \\
0 & A & B & C \\
0 & - & - & - \\
1 & + & - & - \\
2 & + & + & - \\
3 & + & + & +
\end{tabular}

i.e. 'additive coding' (Sneath, 1962). In this way we codified, for example, the percentage of acid-fast organisms or the drug-resistance.

(b) For the growth rate and growth ability the following coding variant was used (see Discussion):

0 No growth in 28 days on $\mathrm{X}$ medium

1 Growth in 15-28 days

2 Growth in 8-14 days

3 Growth in 4-7 days

4 Growth in -3 days

$\begin{array}{cccc}\mathbf{A} & \mathbf{B} & \mathbf{C} & \mathbf{D} \\ - & - & \mathrm{NC} & \mathrm{NC} \\ + & - & - & - \\ + & + & - & - \\ + & + & + & - \\ + & + & + & +\end{array}$

$\mathrm{NC}=$ no comparison.

(2) Characters subordinated to other characters (Silvestri et al. 1962), for instance: emulsibility 'yes' or 'no'; if 'yes', high or low:

$\begin{array}{lll} & \text { A } & \text { B } \\ \text { Yes, high } & + & + \\ \text { Yes, low } & + & - \\ \text { No } & - & \text { NC }\end{array}$

(3) For pigmentation in the dark we used a special coding:

\begin{tabular}{|c|c|c|}
\hline Colour of the culture & $\begin{array}{l}\text { Presence of } \\
\text { pigment } \\
\text { (A) }\end{array}$ & $\begin{array}{l}\text { Red pigment } \\
\text { (B) }\end{array}$ \\
\hline
\end{tabular}

$\begin{array}{ll}1 & \text { White-grey } \\ 2 & \text { Yellowish } \\ 3 & \text { Lemon-yellow } \\ 4 & \text { Dull-orange } \\ 5 & \text { Bright-orange }\end{array}$

Table 2 shows the characters examined, the number of features given for each character and the coding method (according to the system used above).

The formation of clusters. The comparison of the strains was made without a computer, determining the matching index between each couple of strains according to:

$$
\% M=n_{c} /\left(n_{c}+n_{d}\right) \times 100,
$$

where $n_{c}=$ the number of concordances (between + and + , and - and - features) and $n_{d}=$ the number of discordances (between + and - features) (Silvestri et al. 1962). For grouping the strains we used a modified Single Link Method (Sneath, 
1962). Each new strain joined one or other end of the nucleus according to its higher $\% M$ with one or other half-cluster. In order to make clustering cleaner it has been necessary to change the position of some strains in the alignment (Sneath \& Cowan, 1958). We also calculated the arithmetic means of the indices within and between the groups.

Table 2. Coding of the characters analysed

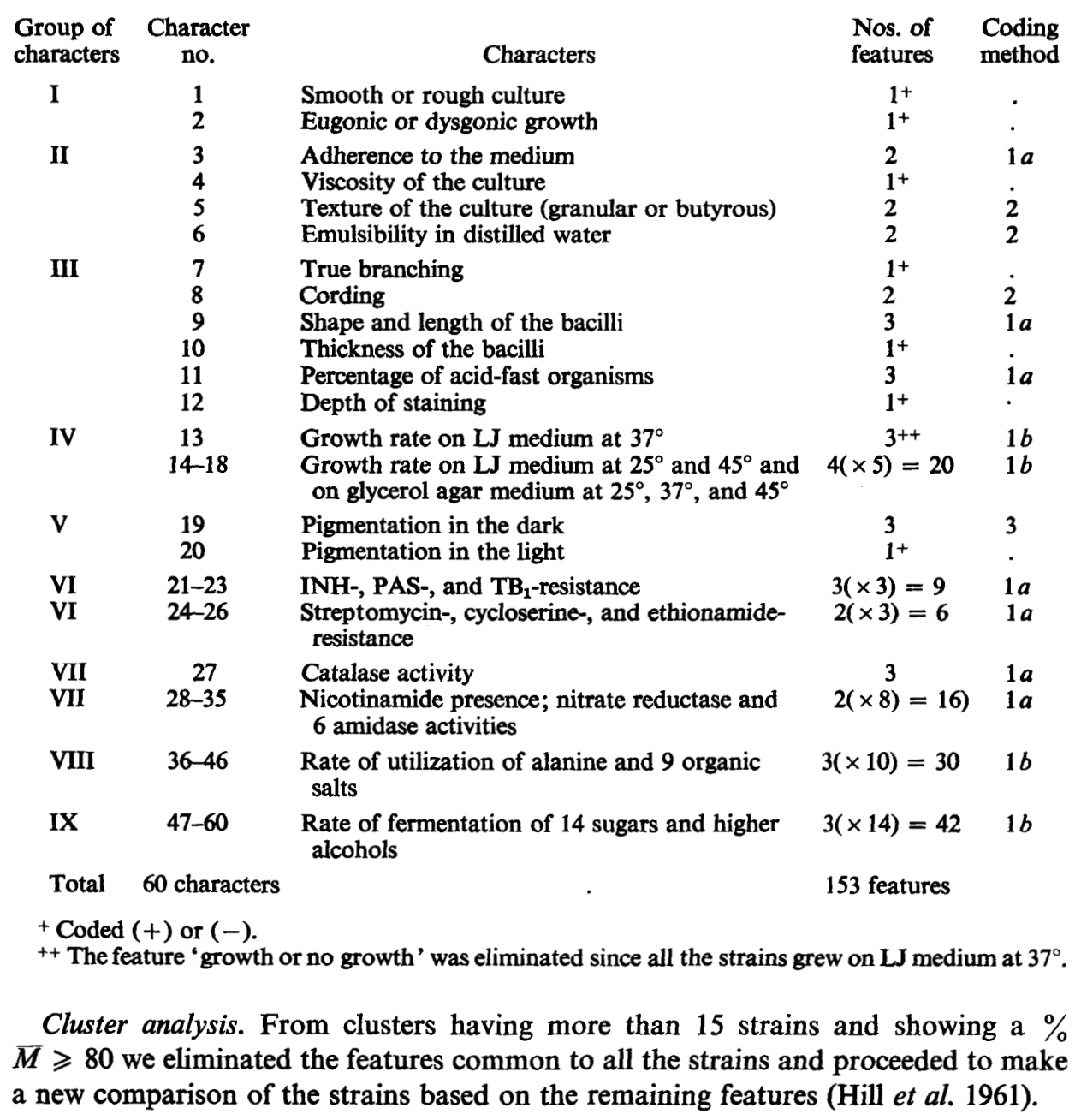

\section{RESULTS}

General Survey

The grouping of the strains in accordance with the $M$ indices is shown in Fig. 1. Five clusters were recognized at the 80-phenon level:

(I) A cluster of 19 strains (80P-I), including the human and bovine control strains (1-7 of Table 1) and 12 strains having some atypical 'key characters' (negative to the 
Konno test, PAS-resistance, dysgonic growth, INH-resistance associated with positive catalase). The mean intragroup index, $\bar{M} \%$, was 85.7 .

(II) A cluster of 45 strains (80P-II) with very inhomogenous pigmentation, including 12 control strains (8-19 of Table 1), i.e. 4 avian strains and 8 strains which were classified in England as belonging to the Ist, IVth, Vth and VIth groups of Marks \& Richards (1962), and 33 newly isolated strains, 3 non-photochromogens and 30 scotochromogens. $\bar{M} \%=84 \cdot 5$.

In this last cluster there were 3 subgroups and 1 aberrant strain (174):

80P-II A: 4 strains received from England included in the Ist group of Marks \& Richards, with $\bar{M} \%=91 \cdot 8$;

80P-IIB: 29 newly isolated strains with orange-red pigmentation $(\bar{M} \%=88 \cdot 2)$;

80P-IIC: 4 avian control strains, 4 strains received from England included in the IVth, Vth and VIth groups of Marks \& Richards, and 3 newly isolated strains $(\bar{M} \%=85 \cdot 8)$.

The strain 174, not comprised in these subgroups, is a scotochromogen too, but has some peculiar characters.

(III) A cluster of 28 strains (80P-III), including one control strain, Mycobacterium fortuitum (strain 20 of Table 1). The majority of the strains are without pigment and are rapid growers $(\bar{M} \%=80 \cdot 1)$.

(IV) A cluster (80P-IV) of 3 newly isolated scotochromogenic strains, with are $\bar{M} \%=81 \cdot 0$.

(V) A cluster (80P-V) of 3 control strains belonging to Mycobacterium smegmatis (strains $22-24$ of Table 1 ); $\bar{M} \%=90.3$.

The five clusters comprise 98 strains. Nine strains could not be included: one control strain (Mycobacterium phlei-strain 21 of Table 1, MP in Fig. 1); 5 newly isolated acid-fast strains and 3 non-acid-fast strains.

The table below shows intra- and inter-cluster mean $\bar{M} \%$ values:

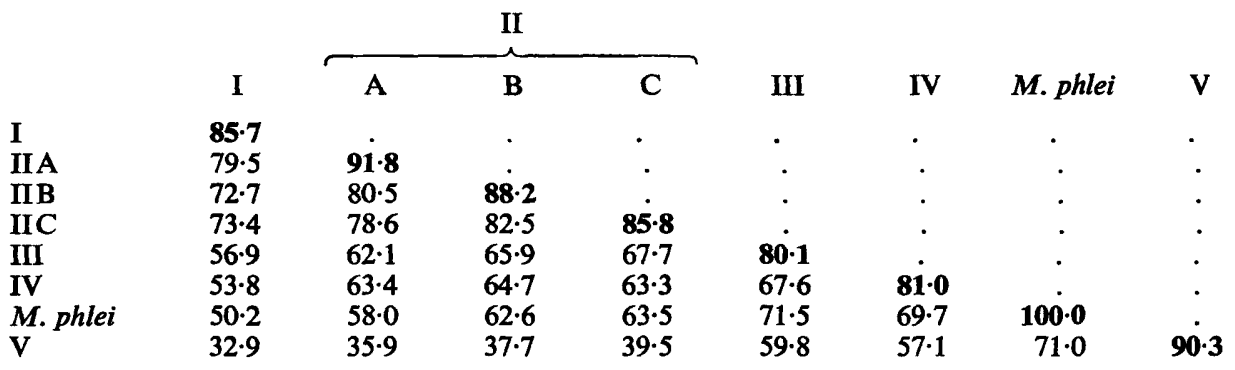

Thus $80 \mathrm{P}-\mathrm{I}$ and $80 \mathrm{P}-\mathrm{II}$ are representing together a 70 -phenon, while Mycobacterium fortuitum group (80P-III) as well as $80 \mathrm{P}-\mathrm{IV}$ and $M$. phlei are obviously different. The $M$. smegmatis group (80P-V) showed a very low similarity with the human, bovine, atypical and avian mycobacteria and a higher one with $80 \mathrm{P}-\mathrm{III}$ and $80 \mathrm{P}-\mathrm{IV}$.

\section{Further analysis of the clusters}

The analysis was carried out as mentioned (see Methods), by recomparing the strains after removing the common features within each group and, when it was possible, by comparing them with the 'hypothetical average organism' (HAO) of the cluster. For rearrangements of the strains according to their similarities, Sneath's 


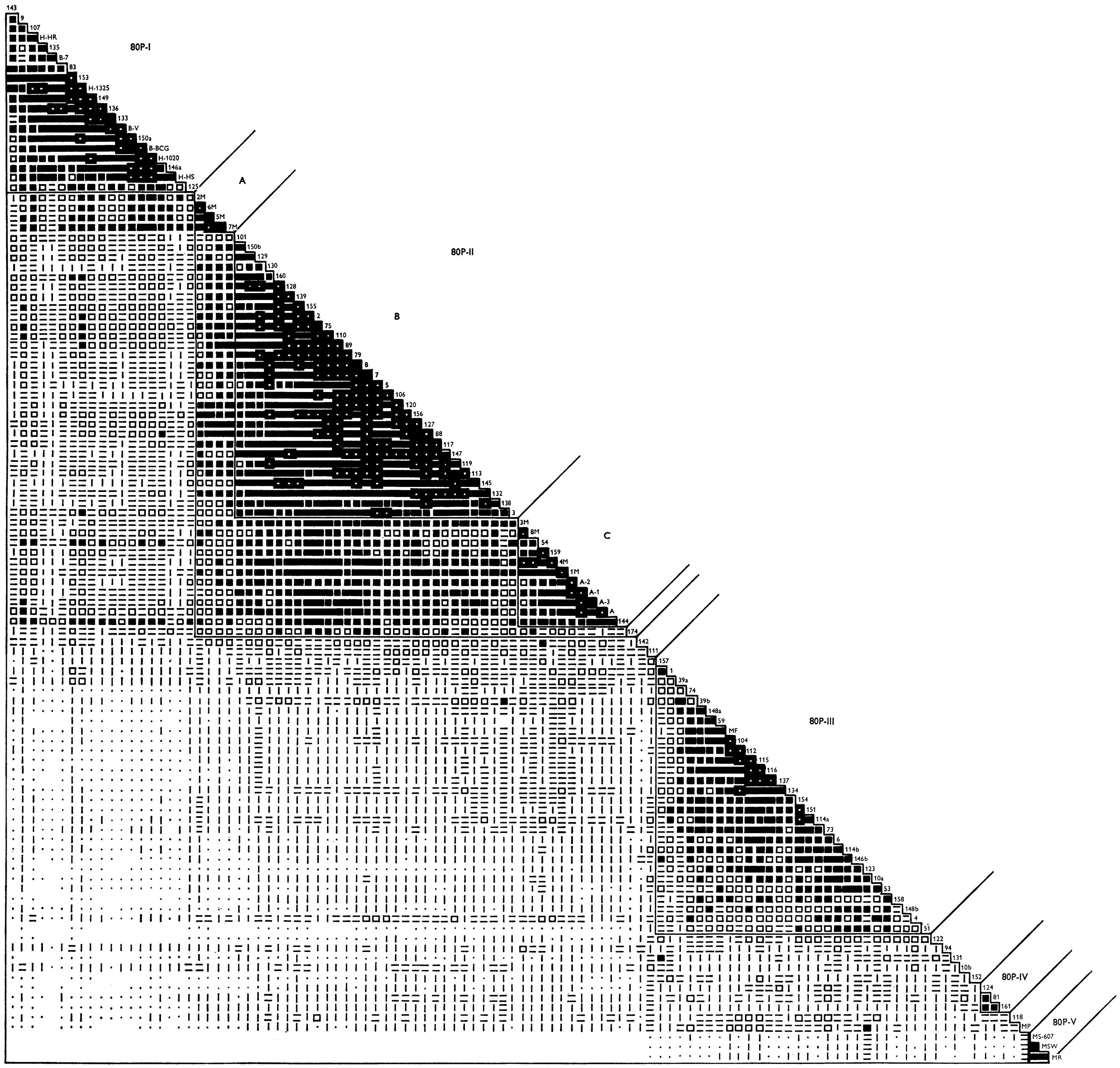

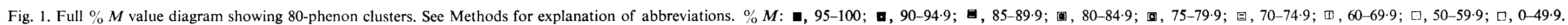


technique (Sneath, 1962) was completed with Silvestri's (Silvestri et al. 1962). The characters of a cluster HAO were simply established by allotting to each feature the majority sign $(+$ or -$)$ in all the strains of that cluster.

The removal of the common features has differentially reduced the number of variable features within each group. The decreasing of $n_{c}$ (in numerators and denominators) lowers the value of $M$, and hence the differences between the strains are accentuated mainly for low values of $M$. At the same time, the percentage of common features is an indication of the homogeneity of the group.

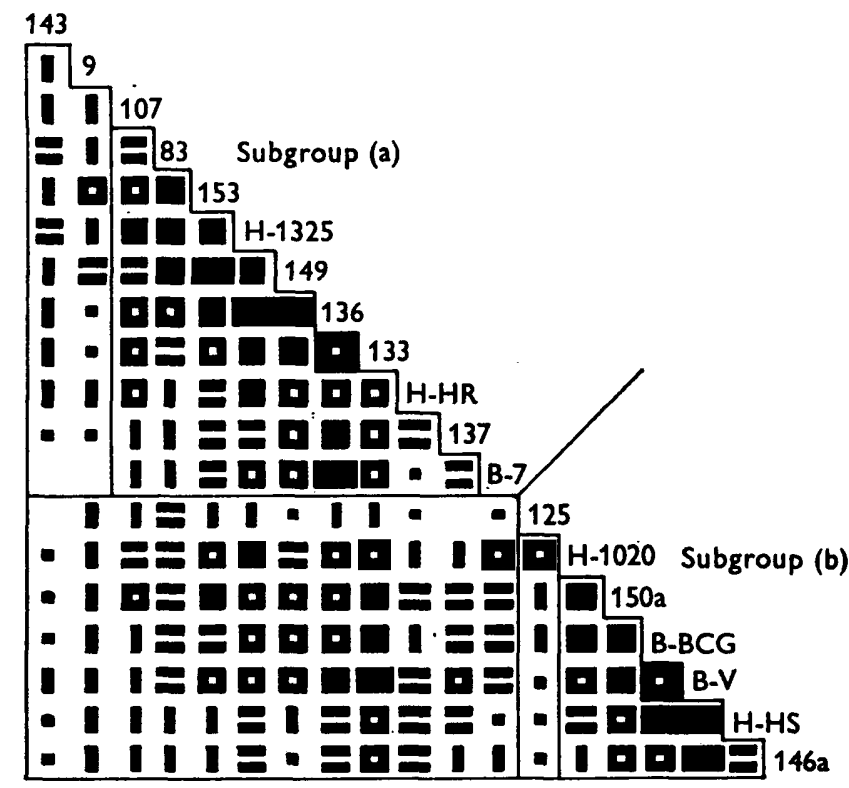

Fig. 2. \% $M$ value diagram of $80 \mathrm{P}-\mathrm{I}$ group after removing the 95 common features, showing two subgroups and three 'aberrant' strains, nos. 143, 9 and $125 . \% M: \square, 95-100 ; \square, 90$

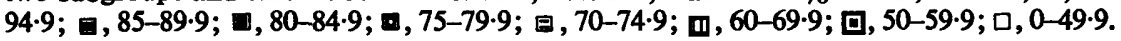

80P-I includes 19 strains, drug-sensitive or with acquired chemoresistance, grouped together with control strains of Mycobacterium tuberculosis of human and bovine type.

By comparing the 58 variable features, left after removing the common ones, two 'nuclei' became evident: (1) the strains 133 and 136; (2) the BCG and Vallée strains. By grouping the other strains around them, two subgroups ensued (Fig. 2). These subgroups do not differ from one another on account of their type (human or bovine) but mainly owing to differences in chemo-susceptibility. Indeed, subgroup $b$ includes only strains susceptible to all the tested drugs, while in subgroup $a$, excepting strains 133 and $B-7$, all the others show different chemoresistance extents to one or another drug. The subgroups do not differ only in chemoresistance: in contrast with the strains of subgroup $b$, most of those belonging to $a$ show dysgonic growth, a less granular texture and better emulsibility, a very slow growth rate on $\mathrm{LJm}$, resistance to $10 \mu \mathrm{g}$. INH and they do not utilize acetate and do not ferment glucose.

$80 P-I I$. The obvious differences in the three subgroups (Fig. 1) require separate analyses. 
In $80 P-I I A$, after the elimination of the common features, only 19 variable features (out of 153) were left. The homogeneity of the 4 strains confirmed both their classification in group I of Marks \& Richards (1962) and the species rank accorded to this group (Mycobacterium kansasii).

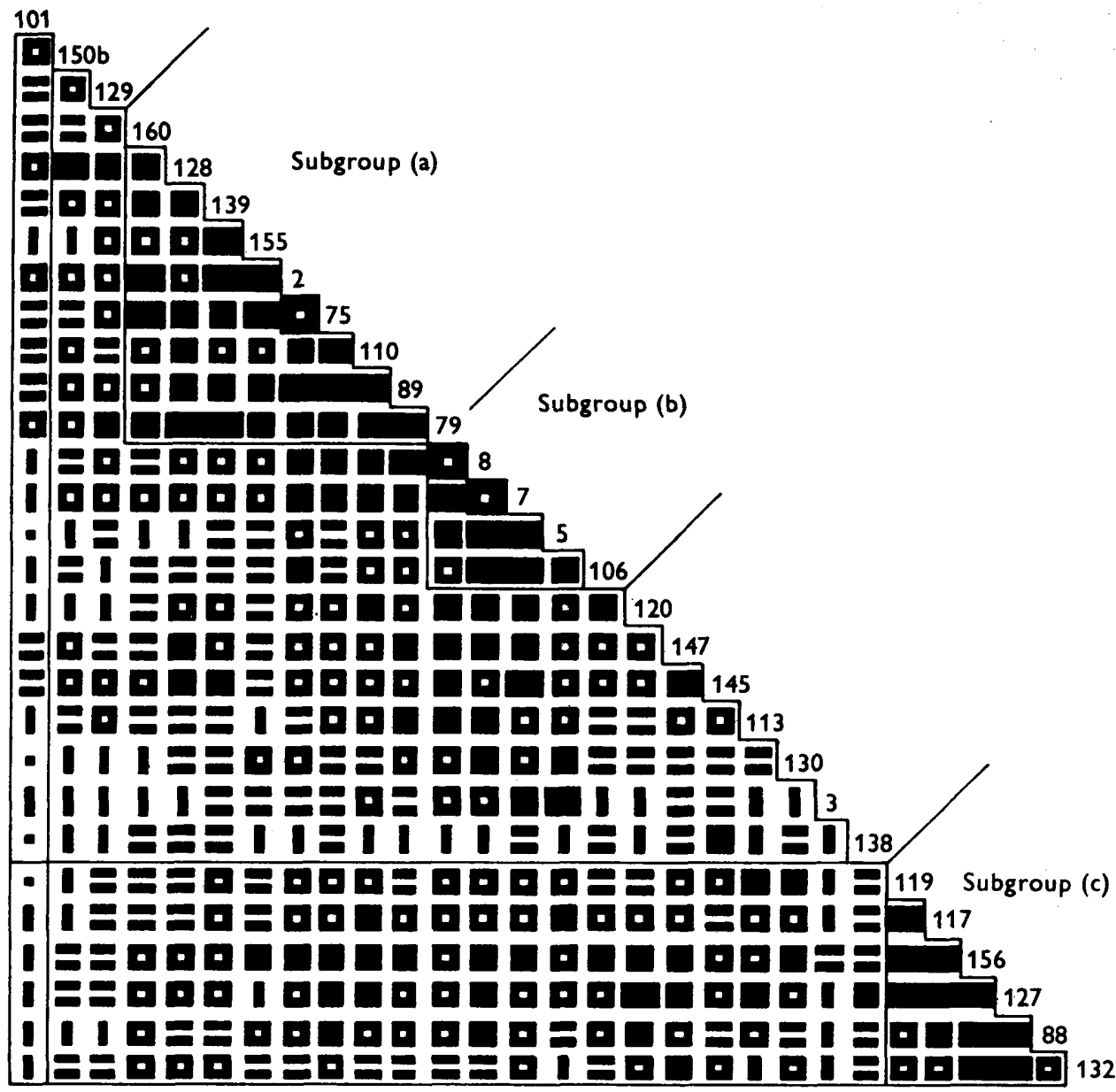

Fig. 3. $\% M$ value diagram of $80 \mathrm{P}-\mathrm{II} \mathrm{B}$ group after removing the 90 common features, showing three subgroups and an 'aberrant' strain, no. 101 (see Table 3). \% $M$ : $0,95-100$;

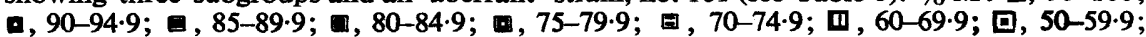
$\square, 0-49 \cdot 9$.

$80 P-I I B$ (29 newly isolated scotochromogenic strains). The review of similarities, based on 63 remaining variable features, has identified a subgroup of 6 strains (subgroup $c$ ). The remaining 23 strains make two other subgroups (subgroups $a$ and $b$ in Fig. 3).

The differences between the three subgroups (statistically estimated upon a majority of characters) appear in the extent of streptomycin, PAS and ethionamide resistance, in urease activity, in acetate utilization rate, in lactate utilization and maltose fermentation. The presence of a bright-orange pigment is a very constant character. 
We established the characters of the HAO for the 80P-IIB group and compared them with each strain of the group (Table 3). Only strain 101 showed an $M$ index of less than $75 \%$ with the HAO. Thus, the group is homogenous, with a relatively low variability.

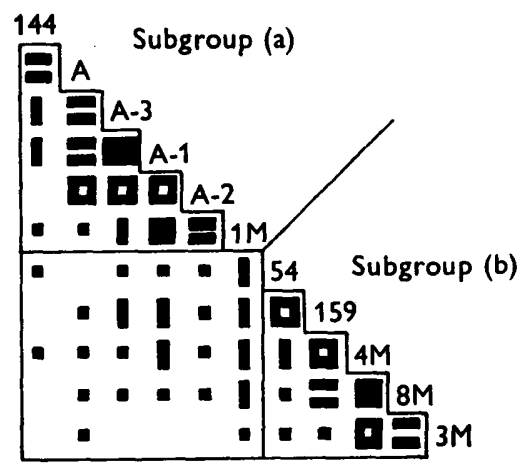

Fig. 4. \% $M$ value diagram of $80 \mathrm{P}-\mathrm{IIC}$ group after removing the 106 common features, showing two subgroups. $\% M: \square, 95-100 ; 0,90-94.9 ; \quad, 85-89.9 ; 0,80-84.9 ; 0,75-79.9$; 曰, 70-74.9; $\mathbb{0}, 60-69 \cdot 9 ;$ 口, 50-59.9; $\square, 0-49.9$.

Table 3. The $\% M$ values of the strains grouped in $80 P-I I B$ with the 'hypothetical average organism' of the same group

$\begin{array}{rrcc}\text { Strain } & \% \boldsymbol{M} & \text { Strain } & \% \boldsymbol{M} \\ 110 & 92 & 5 & 84 \\ 7 & 92 & 119 & 84 \\ 106 & 90 & 88 & 84 \\ 2 & 89 & 147 & 82 \\ 75 & 89 & 113 & 81 \\ 89 & 89 & 130 & 81 \\ 79 & 89 & 160 & 80 \\ 8 & 89 & 128 & 80 \\ 156 & 89 & 150 b & 79 \\ 139 & 87 & 3 & 79 \\ 120 & 87 & 132 & 79 \\ 117 & 87 & 138 & 76 \\ 127 & 86 & 129 & 75 \\ 155 & 84 & 101 & 69 \\ 145 & 84 & & \end{array}$

80P-IIC (11 strains). After the elimination of the common features, 47 variable features remained, and the comparison based upon them differentiated two subgroups (Fig. 4): one, $a$, included all the avian strains, the control strain $1 \mathrm{M}$ (belonging to Marks \& Richards IVth group, considered by these authors as including avian type strains) and one newly isolated strain; the other, $b$, included three control strains classified in the Vth and VIth Marks \& Richards groups and two newly isolated ones. Only four strains in $a$ and two strains in $b$ grew on $\mathrm{LJm}$ at $45^{\circ}$.

The characters which clearly differentiated subgroup $a$ are: a relatively slow growth (at least 15 days on $\mathrm{LJm}$ at $25^{\circ}$ and 7 days at $37^{\circ}$ ), $\mathrm{Th}$ - and $\mathrm{TB}_{1}$-resistance, a positive nitrate reductase test, and a more rapid lactate utilization (in most cases in 20 days).

80P-III (28 strains, including the control strain Mycobacterium fortuitum) showed 
a greater variability. Six strains originated from three dissociated strains by mouse passage $(39 a, b ; 114 a, b ; 148 a, b)$. Only 53 features were common to all the strains of the group.

A comparison based upon the 100 variable features gave two subgroups differentiated by culture consistency and adherence to the medium, by the appearance or

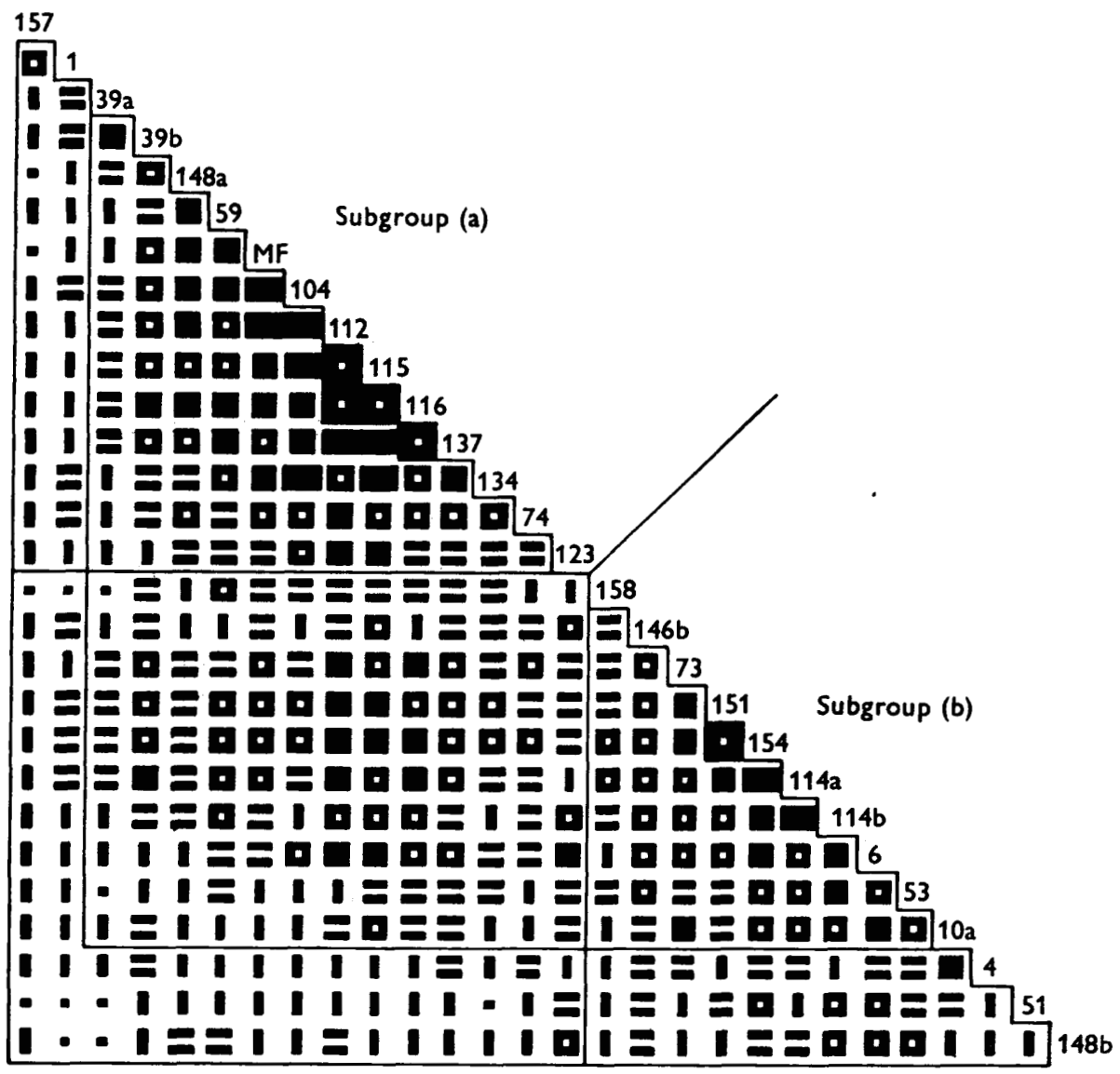

Fig. 5. \% $M$ value diagram of $80 \mathrm{P}$-III group after removing the 53 common features, showing two subgroups and five 'aberrant' strains, nos. 157, 1, 4, 51 and $148 b$ (see Table 4).

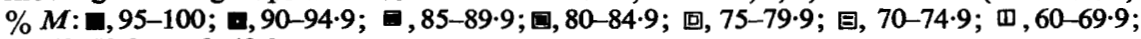
ㅁ, 50-59.9; $\square, 0-49 \cdot 9$.

not of a faint yellowish pigmentation, by the growth rate at $25^{\circ}$, by ethionamide- and $\mathrm{TB}_{1}$-resistance, by acetate and succinate utilization rate, and by glucose, mannose and trehalose fermentation rates (Fig. 5).

Some strains of the group are slow growers $(157,1,39 a, 39 b, 10 a, 4)$, and others did not grow on glycerol agar at $37^{\circ}(1,114 a, 6)$. Strain 74 grew on $\mathrm{LJm}$ at $45^{\circ}$.

The peripheral strains of the subgroups showed relatively low similarities with the nuclei. The overall similarity analysis between the strains and the HAO of the group showed the deviation of these strains from this mean value (Table 4). If we consider 
as a limit of the 'species' a $75 \% M$ value against the HAO, the strains $157,1,4,148 b$ and 51 would not be included in the group.

$80 P-I V$ included only three newly isolated scotochromogenic strains, dull-orange pigmented (excepting the bright-orange pigmented strain 81 ), having short rods (less than $1 \mu$ ), intermediate growth rates, and greater metabolic abilities. Their number does not allow a more detailed statistical analysis.

$80 P-V$ is composed of three Mycobacterium smegmatis control strains with no newly isolated strains. Because of the low number of strains and the high $\bar{M}$ of the group, no statistical problems are raised.

Table 4. The \%M values of the strains grouped in $80 P-I I I$ with the 'hypothetical average organism' of the same group

$\begin{array}{cccc}\text { Strain } & \% M & \text { Strain } & \% M \\ 112 & 91 & 74 & 81 \\ 151 & 91 & 148 a & 80 \\ 154 & 91 & 146 b & 80 \\ 115 & 89 & 10 a & 80 \\ 114 a & 89 & 39 a & 79 \\ 116 & 88 & \text { MF } & 79 \\ 39 b & 87 & 158 & 79 \\ 137 & 85 & 123 & 77 \\ 73 & 85 & 53 & 77 \\ 114 b & 84 & 1 & 74 \\ 104 & 83 & 4 & 74 \\ 134 & 83 & 148 b & 74 \\ 6 & 83 & 51 & 71 \\ 59 & 81 & 157 & 69\end{array}$

\section{DISCUSSION}

In order to achieve objectivity regarding numerical taxonomy, two conditions are supposed to be fulfilled: (1) the analysis of as many characters as possible, and (2) their comparison based upon a uniform coding method.

It is probable that, in our study, the addition of new mycobacterial characters would define more accurately the relative position of the strains. For instance, the impossibility of distinguishing by the tests used, in the presence of acquired chemoresistance, between the Mycobacterium tuberculosis strains and the $M$. bovis strains might raise discussion. Nevertheless, some classifications include both human and bovine tubercle bacilli in one species, M. tuberculosis (Topley and Wilson's Principles, 1964).

Since the 80P-I group, which includes weakly metabolizing and slowly growing strains, is shown mainly on the basis of negative features, further study using more characters is indicated.

As to the second condition, there have been several suggestions. Thus, the inclusion of negative matches as similarities (Hill et al. 1961; Silvestri et al. 1962) is considered by Sneath (1962) as distorting the results if the organisms are very diverse. Of course, if the inclusion of negative features increases the similarity percentages, then excluding them will decrease the number of comparisons- a great statistical disadvantage. Moreover, as Beers \& Lockhart (1962) showed, the negative score $(-)$ has in many cases a conventional value, not meaning the lack of a definite character but the opposite of a character marked with $(+)$ (for instance, drug resistance versus susceptibility). 
Sneath (1962) suggests care when comparing negative features, since, for instance, the inability of a given strain to ferment glucose will bring about its inability to ferment any other sugar. This was seen in most cases in our data, but it has underlined the similarity between strains with extremely weak metabolic capacity, increasing the human and bovine group up to $80 \mathrm{P}$ value, i.e. to a comparable similarity level with the other groups. It does not seem logical to consider the Mycobacterium smegmatis group have a higher similarity level than the $M$. tuberculosis group solely because the comparisons consider only the features marked $(t)$. Moreover, further analysis of the group, involving the elimination of the common features, removes this 'similarity excess'. It must be mentioned that an attempt made to compare the 80P-I strains solely on the basis of the $(+)$ features did not resolve the problems discussed above.

Inclusion of the $(-)$ features leads to an alignment with all the samples of the genus Mycobacterium we had at our disposal arranged along a gradient of fermentative ability, beginning with $M$. tuberculosis (human and bovine types) and ending with M. smegmatis.

Finally, using the same argument as Beers \& Lockhart (1962), if one considers that inability to ferment sugars is not due to the lack of genes but to the activity of repressors, theoretically the fermentation inability might be marked with $(+)$, i.e. repressor activity, and the reverse with $(-)$, repressor inactivity.

In subdividing the characters into features we preferred the 'additive codification' (Silvestri et al. 1962). Sneath (1962) shows that the non-additive method does not afford any information concerning the degree of difference between different characters. With regard to the genus Mycobacterium, not only the metabolic abilities scored as 'yes' or 'no', but also the rate of utilization of the substrate plays a prominent part in differentiation (Wayne, 1964).

We must still give the reasons that led us to use for some characters the coding method we have marked $1 b$ (Methods). It was of the following type:

$\begin{array}{llcccc} & & \text { A } & \text { B } & \text { C } & \text { D } \\ 0 & \text { No growth in 28 days on X medium } & - & - & \text { NC } & \text { NC } \\ 1 & \text { Growth in 15-28 days } & + & - & - & - \\ 2 & \text { Growth in 8-14 days } & + & + & - & - \\ 3 & \text { Growth in 4-7 days } & + & + & + & - \\ 4 & \text { Growth in 1-3 days } & + & + & + & +\end{array}$

Thus, the additive method was used only in comparing variants $1-4$. In this way the matching indices $(M)$ between the 0 variant and the variants $2-4$ are equal $(M=0 \%)$. On the other hand we did not score total incompatibility between variants 0 and 1 , since a strain that did not grow in 28 days is potentially still able to grow. Therefore, between a strain with behaviour 0 and a strain with behaviour 1 , $M$ will be $50 \% \cdot M_{0,1}$ will be hence equal to $50 \%$ as well as $M_{1,3}$ or $M_{2,4}$, but having a lower 'weight', since $M_{0,1}$ is codified only by two features while $M_{1,3}$ or $M_{2,4}$ are codified by 4 features.

'Character weight' also introduces a subjective element in weighting of the characters. For instance, we were subjective in giving only one feature to photochromogenicity but three for the scotochromogenicity; we gave two features for streptomycin-, ethionamide-, and cycloserine-resistance but three for INH-, PAS-, and TB-resistance etc. (Table 2).

The pathogenicity of Mycobacterium tuberculosis led to the neglect for a long time 
of the related species, thus distorting the objective biological study of the whole genus (Wayne, 1964). The increasingly frequent isolation of 'atypical' strains showed the need for more knowledge. Runyon's classification, based upon a few characters, was extremely useful for a rapid and rough identification. Attempts to improve it (Collins, 1962) or to achieve classification according to practical (medical) criteria (Kagramanov, 1963; Buraczewska, 1963) have been made. The tentative classification of Marks \& Richards (1962) also aims at a practical purpose, in studying only potentially pathogenic strains. They emphasized that the Vth, VIth and VIIth groups were provisional, and should be studied by overall similarity analysis. The studies of Bönicke (1960), Cerbón \& Trujillo (1963), Morellini et al. (1964) tried to cover the whole genus, but the differentiation of species was based on key characters.

By using overall similarity analysis the groups of strains fell into a definite order. The extreme position of Mycobacterium smegmatis was also pointed out by Bojalil et al. (1962) using the same method. $M$. tuberculosis, usually placed in the centre of the genus, becomes, when one considers interspecific relationships, a peripheral species which has peculiar characters because of its specialization.

We have already shown that the two subgroups in 80P-I are differentiated to a great extent by the chemoresistance of the strains, with which other differences are also associated. It seems logical to ask whether difference in pathogenicity, which is the main distinction between the two 'species' Mycobacterium tuberculosis and M. bovis, is any more important that the character of INH-resistance. The recent research of Cattaneo, De Ritis \& Lucchesi (1965) has shown differences between the fatty-acid content of the INH-susceptible and INH-resistant tubercle bacilli.

As to Mycobacterium kansasii, the key character of photopigmentation might seem well chosen, but according to Bojalil et al. (1962). M. marinum also has this character and it is also found in $M$. balnei, $M$. scrofulaceum, M. marianum, and sometimes in $M$. aquae type I and $M$. battaglini (Morellini et al. 1964). Hauduroy, Hovanessian \& Roussianos (1965) show that even in M. kansasii photochromogenicity is a secondary and unstable character, which should only be used for a first orientation. Consequently, a photochromogen does not necessarily belong to $M$. kansasii and a strain of this species is not necessarily a photochromogen. The high similarity values between 80P-II A and 80P-I support the opinion of Weissfeiler, Karassova \& Holland (1964) that $M$. kansasii has been derived by mutation from $M$. tuberculosis.

The 80P-IIB subgroups (Fig. 3) were distinguished neither by their amidase activities nor by their capacity to ferment mannose, by which Bojalil et al. (1962) distinguished Mycobacterium marianum from M. gordonae.

The probability that the Battey strains belong to Mycobacterium avium has been emphasized many times. Wayne \& Doubek (1963), using overall similarity analysis, differentiated three subgroups in the IIIrd Runyon group, only one of which was potentially pathogenic and which perhaps belonged to the Battey-avian-porcine complex. Since the tests used by them are not the same as ours, we cannot compare them further. On our data the 80P-IIC group, although numerically scanty, could be split into two subgroups, but the key character of growth at $45^{\circ}$ seems of little use for differentiating this complex of strains. Not all the strains in the 80P-III group possessed the key characters commonly used for the identification of Runyon's IVth group (rapid growth, growth on glycerol agar at $37^{\circ}$ ).

There is great similarity between the 80P-II subgroups (A, photochromogens 
B, scotochromogens; $C$, avian complex of strains). The scotochromogenic mycobacteria are generally not pathogenic, but their isolation from human pathological products is very frequent, in contrast with the saprophytic mycobacteria (Mycobacterium phlei, M. smegmatis). Their relationship with the pathogenic groups (pointed out in recent work: Siebenmann \& Barbara, 1964; Koyama, 1964; Kassirskaia \& Mencikov, 1965) raises the question of close genetic connexions which would deserve more thorough examination. The scotochromogenic strains in the 80P-IV group could not be identified as belonging to any of the species of Bojalil et al. (1962) or Morellini et al. (1964). We do not wish to propose a new species for these strains. However our failure to identify them with any of Bojalil's or Morellini's species emphasizes that it is sometimes impossible to identify mycobacteria by key characters.

The strains which could not be grouped raise a similar question. Most likely they would represent unique strains belonging to certain definite groups (species), but they cannot be identified further in the present state of our knowledge. There are also strains that were initially clustered but which were subsequently eliminated by the second analysis. These aberrant strains might be considered either as variants arising as an effect of unknown agents, or as mixtures (either mixed cultures or genetic hybrids) belonging to different groups. The latter explanation is possible since we have five strains which dissociated on culture. These five strains raise genetic problems. Most of them are on the periphery of the group to which they belong: strains $146 a$ (Fig. 2); $150 b$ (Fig. 3); 39a, 39b, 146b, 10a, $148 b$ (Fig. 5). They even occur outside any group (strain 10b, Fig. 1). The pairs with very similar partners, such as $39 a$ and $b, 114 a$ and $b$ (Fig. 5), differ by one or two obvious characters (pigmentation, consistency), and thus may give clues about the first steps in the variation of mycobacteria.

In conclusion, from the results obtained both by us and others, overall similarity analysis seems to be the best method, for the time being, for systematizing this group. By this method, both Bojalil et al. (1962) and ourselves were able to group mycobacteria according to their relative affinity. This work revealed a great similarity between the slowly growing 'atypical' mycobacteria, and moreover the present study has shown the close relationship between them and Mycobacterium tuberculosis. Our work also shows, however, the considerable variability of strains isolated from human pathological material and the difficulty of identifying them.

To produce an adequate taxonomic revision of this genus would require a comprehensive overall similarity analysis of a large number of pure strains (both from collections and newly isolated) from all over the world, and from all the environments where mycobacteria live. Standardized tests and coding methods would be needed. An international reference centre could establish on this basis the groups (phenons, species) and subgroups (phenons, varieties) as well as the characters of the corresponding 'hypothetical average organism' or 'hypothetical median organism' (Liston et al. 1963). When comparing an unknown strain with these 'hypothetical organisms' it would be sufficient to use only those characters which proved to be significant as a result of a statistical estimation (Beers \& Lockhart, 1962). Thus, newly isolated strains from various countries would be correctly placed by such comparisons. This would solve both the present points of controversy-the theoretical one regarding the classification and the practical one regarding the identification of mycobacterial strains. 
The authors are indebted to $\mathrm{Dr} \mathrm{C}$. Vior and Dr Cambir, from the 'Institutul de Patologie Animală' in Bucharest, who kindly supplied the eight strains they received from England.

\section{REFERENCES}

BeERs, R. J., \& Lockhart, W. R. (1962). Experimental methods in computer taxonomy. J. gen. Microbiol. 28, 633.

Beers, R. J., Fisher, J., Megraw, S. \& Lockhart, W. R. (1962). A comparison of methods for computer taxonomy. J. gen. Microbiol. 28, 641.

Bogdanescu, V., Bungetianu, G. \& Racotta, R. (1965). Frequency of isolation of atypical Mycobacteria from a restricted area and correlations between the clinico-radiological and bacteriological aspects. 18th Int. Tuberc. Conf., Munich.

BOJALI, L. F. \& CERBóN, J. (1961). Taxonomic analysis of non-pigmented, rapidly growing Mycobacteria. J. Bact. 81, 338.

Bojalil, L. F., Cerbón, J. \& Trujillo, A. (1962). Adansonian classification of Mycobacteria. J. gen. Microbiol. 28, 333.

BONICKE, R. (1960). Die Klassifizierung 'atypischer' Mycobakterien durch Bestimmung ihren unterschiedlichen acylamidatischen Stoffwechselleistungen. Tuberkulosearzt 14, 209.

BurACZEWSKA, M. (1963). Attempts at classification and identification of atypical bacilli. Gruzlica 31, 748.

CANETti, G., Rist, N. \& Grosset, J. (1963). Mesure de la sensibilité du bacille tuberculeux aux drogues antibacillaires par la méthode des proportions. Rev. Tuberc. Pneumol. 27, 217.

Cattaneo, C., De RITIS, G. C. \& LuCCHESI, M. (1965). Separation of fatty acids from mycobacteria by gas chromatography. 18th Int. Congr. Tuberc., Munich.

CERBON, J. \& BojalI, L. F. (1961). Physiological relationships of rapidly growing mycobacteria. Adansonian classification. J. gen. Microbiol. 25, 7.

Cerbon, J. \& TruJlllo, A. (1963). A comparison of methods for the classification of mycobacteria. Utilization of carbon sources and deamidase tests. Am. Rev. resp. Dis. 88, 546.

Classification and nomenclature of mycobacteria (1962), Lancet ii, 1153.

Collns, C. H. (1962). The classification of 'anonymous' acid-fast bacilli from human sources. Tubercle, Lond. 43, 292.

COlWELl, R. R. \& Liston, J. (1961). Taxonomic relationships among the pseudomonads. J. Bact. 82, 1.

COLWELL, R. R. \& MANDEL, M. (1964). Adansonian analysis and deoxyribonucleic acid base composition of some Gram-negative bacteria. J. Bact. 87, 1412.

Colwell, R. R. \& MANDEL, M. (1965). Adansonian analysis and deoxyribonucleic acid base composition of Serratia marcescens. J. Bact. 89, 454.

Floodgate, G. D. (1962a). Some comments on the Adansonian taxonomic method. Int. Bull. bact. Nomencl. Taxon. 12, 171.

Floodgate, G. D. (1962 b). Some remarks on the theoretical aspects of bacterial taxonomy. Bact. Rev. $26,277$.

GILARDI, E., Hill, L. R., TURRI, M. \& Silvestri, L. G. (1960). Quantitative methods in the systematics of Actinomycetales. I. G. Microbiol. 8, 203.

Gordon, R. E. \& SMrth, M. (1953). Rapidly growing, acid-fast bacteria. I. Species description of Mycobacterium phlei, Lehmann \& Neumann and Mycobacterium smegmatis (Trevisan,) Lehmann \& Neumann. J. Bact. 66, 41.

Hauduroy, P., Hovanessian, A. \& Roussianos, D. (1965). Instabilité de la chromogénéité des souches de Mycobacterium kansasii. Ann. Inst. Pasteur 109, 142.

Heywood, V. H. \& MCNeml, J. (1964). Phenetic and phylogenetic classification. Nature, Lond. 203, 1220.

Hill, L. R. (1959). The Adansonian classification of the staphylococci. J. gen. Microbiol. $20,277$.

Hill, L. R., TURri, M., Gilard, E. \& Silvestri, L. G. (1961). Quantitative methods in the systematics of Actinomycetales. II. G. Microbiol. 9, 56.

JUHLIN, I. (1960). Methods for the grouping and typing of mycobacteria. Acta path. microbiol. scand. $50,177$.

Kagramanov, A. I. (1963), Sur les mycobactéries acido-résistantes atypiques. Probleme Tuberc. 7, 69.

KÄPPLER, W. \& JANOWIEC, M. (1963). Untersuchungen über die Identifizireung und Klassifizierung von photochromogenen Mycobakterien (Gruppe I). I. Versuche in vitro. Beitr. Klin, Tuberk. 126, 202.

Kassirskala, N. G. \& Mencikov, D. D. (1965). Facultés immunogéniques des mycobactéries atypiques. Probleme Tuberc. no. 6, 64. 
Kendrick, W. B. \& Proctor, J. R. (1964). Computer taxonomy in the fungi imperfecti. Can. J. Bot. 42, 65 .

KonNo, K. (1960). Reliability of the niacin test. Am. Rev. resp. Dis. 82, 422.

KOYAMA, K. (1964). Experimental studies on immunizing effect of unclassified acid-fast bacilli against tuberculous infection. I. Observations on survival days of mice immunized with various strains of unclassified acid-fast bacilli and infected with bovine type tubercle bacilli. Kekkaku 39, 64 .

Liston, J., Wiebe, W. \& ColWell, R. R. (1963). Quantitative approach to the study of bacterial species. J. Bact. 85, 1061.

LySENKo, O. \& SNEATH, P. H. A. (1959). The use of models in bacterial classification. J. gen. Microbiol. $20,284$.

Manion, R. E., Bradley, S. G., Zinneman, H. H. \& Hall, W. H. (1964). Interrelationships among Mycobacteria and Nocardiae. J. Bact. 87, 1056.

MARKS, J. H. \& RichaRds, M. (1962). Classification of the anonymous Mycobacteria as a guide to their significance. A preliminary study. Mon. Bull. Minist. Hlth 21, 200.

Marmur, J., Falkow, S. \& MANDel, M. (1963). New approaches to bacterial taxonomy. A. Rev. Microbiol. 17, 329.

Morellin, M., Cattaneo, C., Ferri, L., Ferrari, S. \& Felicetti, L. (1964). Contributto alla risoluzione dei problemi relativi alla tipizzazione dei micobatteri. Nota I, II. Annali Ist. Carlo Forlanini 24, 33.

NASTA, M. \& Bogdanescu-Cioclov, V. (1959), Le problème des bacilles acido-résistants dits 'Atypiques'. Bull. Un. int. Tuberc. 29, 363.

PEIZER, L. \& WideLOCK, D. (1955). A colorimetric test for measuring catalase activity of Mycobacterium tuberculosis. Am. Rev. Tuberc. 71, 807.

Proctor, J. R. \& KendRICK, W. B. (1963), Unequal weighting in numerical taxonomy. Nature, Lond. 197, 716.

REYNOLDS, K. A. (1965). Numerical taxonomy and comparative elaborateness, with a speculation on unused genes. Nature, Lond. 206, 166.

RUNYON, E. H. (1959). The recognition and characterization of pulmonary mycobacterial pathogens other than tubercle bacilli; a review. Bull. Un. int. Tuberc. 39, 396.

SATtLer, R. (1963). Numerische Taxonomie. $Z$. Bot. 51, 340.

SIEBENMANN, C. O. \& BARBARA, C. (1964). Immunologic relationships between typical and atypical mycobacteria as studied by means of the mouse protection test. Am. Rev. resp. Dis. 89, 20.

Silvestri, L. G. \& HinL, L. R. (1965). Agreement between deoxyribonucleic acid base composition taxometric classification of Gram-positive cocci. J. Bact. 90, 136.

Silvestri, L. G., TURRI, M., HIIL, L. R. \& GiLARDI, E. (1962). A quantitative approach to the systematics of Actinomycetes based on overall similarity. Symp. Soc. gen. Microbiol. 12, 333.

SNEATH, P. H. A. (1957). The application of computers to taxonomy. J. gen. Microbiol. 17, 201.

SNEATH, P. H. A. (1962). The construction of taxonomic groups. Symp. Soc. gen. Microbiol. 12, 289.

SNEATH, P. H. A. \& CoWAN, S. T. (1958), An electro-taxonomic survey of bacteria. J. gen. Microbiol. $19,551$.

Sokal, R. R. \& Sneath, P. H. A. (1963), Principles of Numerical Taxonomy. San Francisco: W. H. Freeman and Co.

Talbot, J. M. \& SNeath, P. H. A. (1960). A taxonomic study of Pasteurella septica, especially of strains isolated from human sources. J. gen. Microbiol. 22, 303.

Topley and Wilson's Principles of Bacteriology and Immunity. (1964). 5th ed. Ed. by G. S. Wilson and A. A. Miles. London: Arnold.

VIRTANEN, S. (1960). A study of nitrate reduction by mycobacteria. The use of the nitrate reduction test in the identification of Mycobacteria. Acta tuberc. scand. 38, suppl. 48, p. 1.

WAYNe, L. G. (1964). The mycobacterial mystique: deterrent to taxonomy. Am. Rev. resp. Dis. 90, 255.

WAYNE, L. G. \& DouBEK, J. R. (1963). Differentiation among several types of group III Mycobacteria. Am. Rev. resp. Dis. 88, 111.

Weissfeiler, J., KARASSOVA, V. \& Holland, J. (1964). Genetic relationship between ' Mycobacterium kansasii' and 'Mycobacterium tuberculosis'. Acta microbiol. hung. 11, 1. 